\title{
Invasive plant has higher resistance to native generalist herbivore than exotic non-invasive congener
}

\author{
Li Chen ${ }^{1}$, Zhen $\mathrm{Liu}^{2}$, Chao $\mathrm{chen}^{2}$, Dan feng $\mathrm{Liu}^{2}$, and Yi Wang ${ }^{2}$ \\ ${ }^{1}$ Affiliation not available \\ ${ }^{2}$ Yunnan University
}

October 12, 2020

\begin{abstract}
Studies on the effects of invasive plants on native herbivores often only concern about short-term effects, and few studies have focused on the long-term effects of invasive plants on herbivores. We investigated the development of Spodoptera litura to the second generation on the invasive plant Phytolacca americana and the exotic non-invasive plant Phytolacca icosandra, meanwhile, we tested the impacts of the P. americana on the S. litura through laboratory bioassay, oviposition preference and detoxifying enzyme activity analysis. The results show that S. litura have feeding and oviposition preference to P. icosandra, the larval weight and oviposition preference index (OPI) of S. litura feeding on P. icosandra are higher. However, the developmental duration of S. litura on P. icosandra is shorter than that of P. americana; the activities of Acetyl cholinesterase (AchE) and Glutathione-S-transferase (GST) of S. litura feeding on the leaves of the P. americana were higher than those of feeding on artificial diet and P. icosandra. There is no significant difference of activities of AchE and GST between S. litura feeding on artificial diet and P. icosandra. These findings have important implications for the evaluation of the impacts of invasive plant P. americana on native herbivores in the local ecosystem and explain that invasive plant has higher resistance to herbivores and suffer less damage than exotic non-invasive plant in the invaded range.
\end{abstract}

\section{Introduction}

Invasive plants were more likely to have novel chemicals than native plants in introduction region (Lankau et al., 2004; Cappuccino \& Arnason, 2006; Schaffner et al., 2011; Macel et al., 2014), these chemicals facilitate exotic plants successful invasion via higher resistance to herbivores and inhibiting native plant growth (Sedio et al., 2020). Many studies indicated that invasive plants suffer less herbivory than non-invasive plants, and the reason for this phenomenon is attributed to the invasive plants possess anti-herbivore chemicals (Cappuccino \& Carpenter, 2005; Schaffner et al., 2011). However, invasive plants as a potential food resource (Schlaepfer et al., 2011) will increase the possibility of being feeding by herbivores as time of invasion increases (Dai et al., 2014). The low adaptability of native insects to invasive plants will form a trap that affects the reproduction and growth of native insects and even causes the extinction of some native insect populations, this phenomenon was reported as ecological trap (Mack et al., 2000; Schlaepfer et al., 2002; Battin, 2004; Sun et al., 2020). The fecundity and performance of insects will be affected by the quality of the host (Awmack \& Leather 2002). Wang et al. (2006) indicated that female insects reared on the plant with higher nitrogen content have greater weight and higher oviposition rate. Rane et al. (2019) found that when Gypsy moths (Lymantria dispar) were fed on artificial diet that lacking protein, vitamins and minerals, the growth rate was slow, the pupae weight was small and the development period was prolonged. Besides, plant defensive chemicals can extend the developmental period of insects, increase their exposure to natural enemies, and increase mortality (Awmack \& Leather, 2002). In the case of nutrition deficiency or presence of high amounts of defensive substances, insects would produce a large number of small eggs or a small number of eggs but a large volume, respectively (Leather \& Burnand, 1987). Under extremely harsh conditions, female aphids 
invest in greater embryonic development or reabsorb embryos (Ward \& Dixon, 1982; Xu et al., 2019), even if female insects have laid eggs, they will reabsorb the eggs and obtain nutrients to extend their life cycle until the next opportunity for oviposition (Leather, 1983; Sequeira \& Dixon, 1996).

Plants are sessile organisms, to defend against herbivorous insects, a series of defense mechanisms are evolved, including long spines, poor palatability, and the production of toxic substances (Lindroth et al., 1990; Wittstock \& Gershenzon, 2002; Schuman \& Baldwin, 2016; Stahl et al., 2018). In order to survive, herbivore insects have also taken corresponding measures to solve this problem, including behavioral avoidance, excretion and detoxification mechanisms (Karban \& Agrawal, 2002; Heckel, 2014; Erb \& Robert, 2016; Stahl et al., 2018). The detoxification enzymes in the midgut of herbivores are effective against toxic substances produced by plants. Detoxification is aimed specifically at the toxic substances of plants (Yi et al., 2018). Common detoxification enzymes are Acetyl cholinesterase(AChE), Carboxylesterase(CarE) and GlutathioneS-transferase(GST) and so on, CarE mainly plays a role in the detoxification of organophosphorus compounds and is involved in the metabolism of foreign substances (Xu et al., 2006). AChE targets organophosphorus and carbamate compounds and GST can metabolize many compounds and directly affect the ability of insects to resist toxic compounds (Enayati et al., 2005). Furthermore, insects convert toxic substances taken into the intestinal tract into more easily absorbed substances by increasing the enzyme activity in the body and at the same time remove unusable substances from the body to reduce damage to themselves (Rane et al., 2019). The poisonous substances that plants produced sometimes are also benefit to herbivores. Several insects could use the poisonous substances of plants to protect themselves from natural enemies by eating plants carrying poisonous substances (Despres et al., 2007) and secrete toxic substances to prevent attacks from natural enemies (Heckel, 2014; Erb \& Robert, 2016).

Most of the researches on the impacts of invasive plants on native herbivores use local plants for comparison to determine the extent of the impact of invasive plants on native herbivorous insects. In this process, the presence of exotic plants is often ignored. Dai et al. (2014) demonstrated that beetles oviposition preference older invader, the results show that the adaptation of native herbivores to exotic plants is related to the time dynamics. There for, comparing the effects of exotic plants on native herbivorous insects and the effects of invasive plants on native herbivorous insects can better reveal the impacts of invasive plants on herbivores. Huang et al. (2020) study found that invasive plants had lesser herbivory and structural defense and greater nutriment than non-invasive plants.

P. americana originated from North America and was introduced into China as an ornamental plant in 1935 (Xu et al., 2006). It has been spreading in several provinces and become an invasive plant in Southern China (Thompson, 1988; Dicke, 1999; Pearson, 2009). Researches on P. americana have focused on the accumulation of heavy metals and the medicinal value of secondary metabolites(Liu et al., 2011; Chaudhury et al., 2018). P. americana can be enriched in several heavy metals as $\mathrm{Mn}$ and $\mathrm{Cd}$, which are stored in the cell wall and vacuole (Liu et al., 2010). The plants of P. americana have high concentration of saponin, which has medicinal value but toxic to herbivores (Wang et al., 2008). In medical science, it has been confirmed that the secondary metabolites in P. americana have antibacterial, antioxidant and anti-malignant cell proliferation effects (Patra et al., 2014; Boo et al., 2015). At the same time, some studies have shown that the content of secondary metabolites of $P$. aericana are higher than that of other Phytolacca members (Kim et al., 2005). P. acinosa is a native congener with P. americana in China. Although Huang et al. (2016) research indicated that the reason for the successful invasion of $P$. americana in China may be the reallocate resources for defense to growth and reproduction. Through our previous field observations, $P$. americana suffer less damage than P. acinosa when they grow in same sites (Liu et al., 2020). In the field and our common garden, Spodoptera litura Fabricius, which is a common native generalist in China and could damage more than 180 plant species from several families, was observed it's feeding on P. americana and $P$. acinose (personal observation).

In this study, we examined the effects of the invasive $P$. americana and exotic non-invasive $P$. icosandra on native herbivore $S$. litura through laboratory biological assays, oviposition preference and detoxification enzyme assay to reveal impacts of invasive plant $P$. americana on native herbivore in native ecosystems. 


\section{Materials and methods}

\section{Plants and insects}

Berries of P. americana and P. icosandra were collected in June 2019 near the hospital of Yunnan University $\left(24^{\circ} 83^{\prime} \mathrm{N}, 102 \mathrm{deg} 85^{\prime} \mathrm{E},\right)$ and Yunnan Agricultural University (25deg13'N, 102deg74'E,), respectively. After being mashed, the seeds were washed and then dried in a dry environment for subsequent experiments. Before germination, seeds were soaked with concentrated sulfuric acid for 10-15 minutes to break dormancy, and then were sterilized by75\% ethanol. After washing3-5 times with purified water, the seeds were transferred to $1 \%$ agar medium and cultured in an incubator $(26 \mathrm{oC}+-1 \mathrm{oC}, 14 \mathrm{~L}: 10 \mathrm{D})$. After two cotyledons were formed, the seedlings were transferred to a plug tray until at least three leaves were fully expanded, and then they were cultivated in flower pots (outer diameter $\mathrm{x}$ height $=17 \mathrm{~cm} \mathrm{x} 14 \mathrm{~cm}$ ) and watered every two days.

The eggs of S. litura were purchased from Yun Ke Biocontrol Company (Henan, China) and then were kept in an incubator $(26.0 \mathrm{oC}+-1,14 \mathrm{~L}: 10 \mathrm{D})$ until hatching. The larvae were reared with artificial diet (purchased from Yun Ke Biocontrol Company). All experiments were conducted with second-instar larvae.

\section{Physiological impacts of invasive plants on native herbivorous insects: laboratory assay}

A larva in a petri dish, 90 repeats per plant. A total of 180 S. litura of second-instar were placed on a $9-\mathrm{cm}$ diameter disposable petri dish lined with moist filter paper and clean leaves of P. americana . Similarly, $S$. litura larvae were reared with the leaves of $P$. icosandra. All petri dishes were placed in a thermostat incubator $(27 \mathrm{oC}+-1,14 \mathrm{~L}: 10 \mathrm{D})$. Petri dishes were refreshed daily with clean filter paper and fresh leaves. The weight of the larvae was recorded every three days. After pupation, the pupae were weighed individually, and then males and females were separated for subsequent mating. Upon eclosion, two pairs of one male and one female were put into a $0.6 \mathrm{~L}$ plastic bottle with the bottom removed and sealed with gauze. Adults were provisioned with $1 \%$ honey water absorbed on cotton and egg laying of S. litura was observed. Then, the second generation experiment was carried out using the eggs of $S$. litura. The plant leaves that the larvae fed corresponded to the previous ones, and the experiment method was the same as the first generation. The duration of each development stage of the larvae was recorded. The experiments stopped until all S.litura died.

\section{Oviposition preference of S. litura}

To examine the oviposition preference of $S$. litura, the larvae were fed with artificial diet until pupae as described above. After pairing was placed in a separate container. Until the $S$. litura emerged, adult of $S$. litura were covered in a shroud, put three pairs in each cage, and at the same time, threeP. americana and P. icosandra plants of the same size were placed along the diagonal in a cage (length $\mathrm{x}$ width $\mathrm{xheight}=1 \mathrm{~m}$ x $1 \mathrm{~m} \times 1 \mathrm{~m}$ ). The number of $S$. litura eggs on the plant leaves was observed and counted daily. Each cage was regarded as a replicate and thirteen replicates were performed for each test. The calculation method for the oviposition preference index is OPI $=$ (the total number of eggs on plant A -the total number of eggs on plant B) / (the total number of eggs on plant A + the total number of eggs on plant B) .

\section{Determination of detoxification enzyme activity}

To test whether feeding on the invasive plant $P$. americana will effect the enzyme activity of $S$. litura, $P$. americanaplants were put in the shroud and second-instar $S$. litura were placed on the leaves of the plant and allowed to feed until the fourth instar, three $P$. americana were placed in each cage(length $\mathrm{x}$ width $\mathrm{x}$ height $=0.75 \mathrm{~m} \times 0.75 \mathrm{~m} \times 0.75 \mathrm{~m}$ ), four $S$. litura larvae were placed in each plant. In the same way, $P$. icosandra plants were placed in the cage for feeding $S$. litura. The preparation of the enzyme stock solution was based on the method of Chen et al. (2008). The activity of detoxifying enzymes, such as glutathione-S-transferase and acetylcholinesterase, were measured. The specific measurement method is based on the instructions of Glutathione S-transferdse (GSH-ST) assay kit (Colorimetric method) and Acetylcholinesterase assay kit Nanjing Jiancheng Bioengineering Research Institute.

\section{Statistical analyses}


Two-way analysis of variance (ANOVA) was used to test the effects on insect performance (i.e. larval weight) of each plant species. Others performance of $S$. litura pupal weight, egg numbers, development duration and OPI were compared by nonparametric t-test. Then, a one-way ANOVA was used, in which we analized intestinal detoxifying enzyme (i.e. AChE and GST) activity ofS. litura. (SPSS 25.0, Armonk, NY, USA),

\section{Results}

\section{S. litura prefers exotic non-invasive plant}

The $S$. litura larvae reared on the leaves of $P$. americana and $P$. icosandra had similar weights on day 12, 21 and 24 of larval development $(P>0.05)$, but the weight of $S$. litura bred on $P$. icosandra was higher than that of $P$. americana on the 15 th and 18th days of larval development $(P<0.005)$ (Fig. 1). The development of the second-generation $S$. litura larvae ware similar to that of the first-generation larvae (Fig. 1). To sum up, the larvae reared on the leaves of $P$. icosandra weighed more than that of $P$. americana. The larvae of first and second generation all showed the same pattern. In addition, no matter which plant was used to feed the $S$. liturasecond-generation larvae weighed less than first-generation larvae (Fig. 1).

The pupal weight and egg number of $S$. litura reared with $P$. americana and $P$. icosandra were not significantly different in the laboratory $(P=0.7861)$ (Fig. 2A and B). There were significant differences between the developmental duration of $S$. litura feeding on isolated leaves of $P$. americana and $P$. icosandra, and the development period of $S$. litura reared on the leaves of $P$. americana was longer than that of $P$. icosandra (Fig. $2 \mathrm{C}, P=0.0147$ ).

\section{Oviposition preference}

In the choice test, although the number of eggs laid by $S$. lituraon the $P$. icosandra and $P$. americana plants had no significant significance (Fig. 3A, $P=0.1902$ ), S. liturafemales preferred to oviposit on $P$. icosandra can be find from oviposition preference index (OPI) (Fig. 3B, $P=0.0103$ ). The environmental choice of female $S$. litura affects the survival rate of the next generation of larvae and the OPI can better reflect the preference of $S$. litura . Obviously, the OPI of P. icosandra is higher than that of P. americana (Fig. 3B), indicating that the female $S$. litura finds it more suitable for the development of larvae compared with $P$. americana.

\section{Detoxification enzyme activity}

The enzymes activity induced by the $P$. americana was higher than that of $P$. icosandra and artificial diet, but there was no significant in the enzyme activity of the latter two (Fig. 4A). GST activity was similar to the results of AChE activity test. Both had high activity when larvae were allowed to feed on $P$. americana. However, the activity of GST in the midgut of larvae fed artificial diets and P. icosandra in the determination of GST activity was small (Fig. 4B).DiscussionThe host plant quality has the impacts for insect's performance and preference (Awmack \& Leather, 2002), larvae development was significant different between host plant species (Andrea et al., 2019). In addition, most invasive plants are phytochemically unique and suffer less herbivory than non-invasive plants (Cappuccino \& Carpenter, 2005; cappuccino \& Arnason, 2006). In this study, we investigated the larval performance of $S$. lituraon $P$. americana and $P$. icosandra, the results show that the larval weight of $S$. litura was higher on $P$. icosandrathan that on $P$. americana on days 15 th and 18th of larval development (Fig. 1). On the whole, the larvae of $S$. lituradevelop better on $P$. icosandra, the development of the larvae from first and second generation showed the same results. This is consistent with most previous studies which have confirmed that phytophagous insects develop poorly on exotic invasive plants (Ditommaso et al., 2010; Dai et al., 2014). However, some results from other studies have found the opposite pattern, Fielding and Conn. (2011) demonstrate that native generalist herbivore Melanoplus borealisprefer to feed invasive weed Crepis tectorum. Possible explanation for these different results is due to species specific.S. litura could grow to the second generation when feeding on $P$. americana but its performance is worse, indicating that $p$. americana has a long-term effect on development of $S$. litura.There was no significant difference in the weight of the pupae of $S$. litura between the two plants, but $S$. litura that had fed on $P$. icosandra produced more eggs compared to P. americana (Fig. 2B). There 
may be because the nutrients provided by $P$. americana are not sufficient for the development of $S$. litura and there are many defensive substances in $P$. americanawhich have negative effects on $S$. litura. The types and quantities of nutrients and defensive substances can also affect the reproduction strategy of insects (Meghan et al., 2016), such as, the number and size of eggs and resource allocation (Awmack et al., 2002). The experiment of rearing $S$. litura larvae on the leaves of $P$. americana and $P$. icosandra was terminated in the second generation because of the death of the larvae and the larvae of third generation could not develop to pupae. In addition to the difference in the number of eggs laid by S. litura, the quality of the eggs should also be different, probably because the resources obtained by the eggs are relatively small and the later development is poor (Meghan et al., 2016), coupled with the influence of nutrients and defense substances, $S$. litura could maintain on $P$. americana just for two generations. In the future, we will monitor the population dynamics of $S$. litura on $P$. americana in the field with caged plants for several generations to confirm this conclusion. In the oviposition preference experiment, $S$. litura laid more eggs on $P$. icosandra plants compared with $P$. americana(Fig. 3A). This result was possibly influenced by the volatile organic compounds released by plants. Volatile organic compounds as an important source of information for insects and insects can judge the suitable of the host plants (i.e quality host) based on volatile organic compounds (Schoonhoven et al., 2005; Tasin et al., 2011) present. The P. icosandra and P. americana are similar in size, the seedlings used in this experiment were the same size. Therefore, it is unlikely that the oviposition location is selected based on the plant's sheltering function and may be because the two plants have different defense chemicals, $P$. americana contains more saponins (Yong et al., 2005), and subsequently less eggs were laid. According to the oviposition preference index of $S$. litura, it is considered that it prefers to lay eggs on the P. icosandra (Fig. 3B). It is more objective to judge the oviposition preference of insects based on the egg-laying quantity of insects only, as some insects will lay greater numbers of eggs on plants in order to improve their own fitness, even if this plant is not conducive to the survival of offspring (Mayhew, 2001). Therefore, when measuring the insect's oviposition preference, the egg production of the insect should be combined with the survival rate of the offspring (Despres et al., 2007). In this experiment, S. litura laid a large number of eggs on $P$. icosandra and during the development of the second generation of larvae, larvae of $S$. litura that fed on the $P$. icosandra showed higher performance, so the $S$. litura laid eggs more preferentially on $P$. icosandra compared to $P$. americana.

Detoxification enzymes are an effective strategy for insects responding to plant defense substances (Heckel, 2014). Insects convert toxic substances taken into the intestinal tract into more easily absorbed substances by increasing the enzyme activity in the body and at the same time remove unusable substances from the body to reduce damage to themselves (Xu et al., 2006). The detoxification enzymes of $S$. litura, which had been fed with $P$. icosandra, $P$. americana, and artificial diet were measured. The activity of AChE and GST of $S$. lituraafter feeding $P$. americana leaves was relatively higher. This demonstrated that the quantity of defensive chemicals in $P$. americana was higher than $P$. icosandra. Francis et al. (2005) tested the GST activity induced byMyzus persicae on secondary metabolites of Brassica plants, and the results showed that the higher GST activity of Myzus persicaemay be for better adaptation to plant secondary metabolites such as glucosinolates and isothiocyanates (Wang et al., 2008). However, in this experiment, during the second generation of $S$. litura larvae, the larval detoxification enzymes were not measured due to the high larval mortality. The specific mechanism of long-term effects on $S$. litura was investigated by examining multiple generations. If the detoxification enzyme activity of the second generation of $S$. litura was different from that of the first generation, on the one hand, it can reflect the mechanism of the influence of $P$. americana , while on the other hand, it can also reflect the adaptation mechanism of $S$. litura on P. americana .

In summary, we found that native generalist $S$. litura prefer exotic no-invasive $P$. icosandra to invasive $P$. americanaand its performance is poorly on $P$. americana. These results showed that the invasive plant $P$. americana has higher negative effect on the native herbivore $S$. litura. These findings have important implications for the evaluation of the impact of invasive plant $P$. americana on native herbivores in the local ecosystem.

\section{ACKNOWLEDGMENTS}


We would like to thank Shi-Qian Yao and Yun-Tao Xiong for feeding insects. This work was supported by the National Key Research and Development Program (2017YFC1200100) and the National Natural Science Foundation of China (31870362).

\section{CONFLICT OF INTEREST}

The authors have no competing interests.

\section{AUTHOR CONTRIBUTION}

LC: planed and designed the research(equal); performed experiments(equal); analyzed data and wrote the paper(equal).ZL: assisted to conduct the experiment(equal). CC:assisted to conduct the experiment (equal). DFL: planed and designed the research(equal); assisted to conduct the experiment(equal); revised the manuscript(equal). YW: planed and designed the research(equal); revised the manuscript(equal).

\section{DATA AVAILABILITY STATEMENT}

The all relevant data for this project may be found athttps://doi.org/10.6084/m9.figshare.13076882.v1 .

\section{References}

Awmack, C.S. and Leather, S.R. (2002) Host plant quality and fecundity in herbivorous insects. Annual Review of Entomology , 47, 817-844. https://doi.

org/10.1146/annurev.ento.47.091201.145300.

Battin, J. (2004) When good animals love bad habitats: Ecological traps and the conservation of animal populations. Conservation Biology , 18(6), 1482-1491. https://doi.org/10.1111/j.1523-1739.2004.00417.x.

Boo, H.-O., Park, J.-H., Woo, S.-H. and Park, H.-Y. (2015) Antimicrobial effect, antioxidant and tyrosinase inhibitory activity of the extract from different parts of phytolacca americana L. Korean Journal of Crop Scienc e, 60(3), 366-373. https://doi.org/10.7740/kjcs.2015.60.3.366.

Callaway, R.M. and Ridenour, W.M. (2004) Novel weapons: invasive success and the evolution of increased competitive ability. Frontiers in Ecology and the Environment, 2(8), 436-443. https://doi.org/10.1890/15409295(2004)002[0436:NWISAT]2.0.CO;2.

Cappuccino, N. and Arnason, J.T. (2006) Novel chemistry of invasive exotic plants. Biology letters, 2(2), 189-93. https://doi.org/10.1098/rsbl.2005.0433.

Cappuccino, N. and Carpenter, D. (2005) Invasive exotic plants suffer less herbivory than non-invasive exotic plants. Biology letters,1(4), 435-438. https://doi.org/10.1098/rsbl.2005.0341.

Chaudhury, H.C., Panda, A.K., Behera, S.K., Mohanty, M., Subudhi, B.B. (2008) Case report on recovery from Japanese encephalitis virus infection by complementary use of phytolacca-mother tincture and in silico analysis. Journal of Herbal Medicine, 14, 22-28. https://doi.org/10.1016/j.hermed.2018.10.001.

Chen, L.Z., Liang, G.M., Rector, B.G., Zhang, J., Wu, K.M., Guo, Y.Y. (2008) Effects of different brush border membrane vesicle isolation protocols on proteomic analysis of Cry1Ac binding proteins from the midgut of Helicoverpa armigera. Insect Science, 15(6), 497-503. https://doi.org/10.1111/j.1744-7917.2008.00238.x.

Dai, H., Lu, X., Zhang, J., \& Ding, J. (2014) Responses of a native beetle to novel exotic plant species with varying invasion history.Ecological Entomology , 39(1), 118-124. https://doi.org/10.1111/een.12072.

Despres, L., David, J.P. and Gallet, C. (2007) The evolutionary ecology of insect resistance to plant chemicals. Trends in Ecology $\&$ Evolution, 22(6), 298-307. https://doi.org/10.1016/j.tree.2007.02.010.

Dicke, M. (1999) Are herbivore-induced plant volatiles reliable indicators of herbivore identity to foraging carnivorous arthropods?Entomologia Experimentalis Et Applicata, 91(1), 131-142. https://doi.org/10.1046/j.1570-7458.1999.00475.x. 
Ditommaso, A., \& Losey, J.E. (2010) Oviposition preference and larval performance of monarch butterflies (danaus plexippus) on two invasive swallow-wort species. Entomologia Experimentalis et Applicata, 108(3), 205-209. https://doi.org/10.1046/j.1570-7458.2003.00089.x.

Enayati, A.A., Ranson, H. and Hemingway, J. (2005) Insect glutathione transferases and insecticide resistance. Insect Molecular Biology, 14(1), 3-8. https://doi.org/10.1111/j.1365-2583.2004.00529.x.

Erb, M. and Robert, C.a.M. (2016) Sequestration of plant secondary metabolites by insect herbivores: molecular mechanisms and ecological consequences. Current Opinion in Insect Science, 14, 8-11. https://doi.org/ 10.1016/j.cois.2015.11.005.

Fielding, D.J., Con, J.S. (2011) Feeding Preference for and Impact on an Invasive Weed (Crepis tectorum) by a Native, Generalist Insect Herbivore, Melanoplus borealis (Orthoptera: Acrididae). Annals of the Entomological Society of America, 104(6), 1303-1308. https://doi.org/10.1603/AN10151.

Francis, F., Vanhaelen, N. and Haubruge, E. (2005) Glutathione S-transferases in the adaptation to plant secondary metabolites in the Myzus persicae aphid. Archives of Insect Biochemistry and Physiology, 58(3), 166-174. https://doi.org/ 10.1002/arch.20049.

Grant, G.G. and Langevin, D. (1995) Oviposition deterrence, stimulation, and effect on clutch size of Choristoneura (Lepidoptera: Tortricidae) species by extract fractions of host and nonhost foliage.Environmental Entomology, 24(6), 1656-1663. https://doi.org/10.1093/ee/24.6.1656.

Heckel, D.G. (2014) Insect Detoxification and Sequestration Strategies.Annual Plant Reviews, 47(3), 77-114. https://doi.org/10.1002/9781118829783.ch3.

Hierro, J.L. and Callaway, R.M. (2003) Allelopathy and exotic plant invasion. Plant and Soil, 256(1), 29-39. https://doi.org/10.1023/A:1026208327014.

Huang, W., Ding, J.Q. (2016) Effects of generalist herbivory on resistance and resource allocation by the invasive plant, Phytolacca americana. Insect Science, 23(2), 191-199. https://doi.org/10.1111/1744-7917.12244.

Huang, K., Kong, D.L., LU, X.M., Feng, W.W., Liu, M.C., Feng, Y.L. (2020) Lesser leaf herbivore damage and structural defense and great nutrient concentrations for invasive alien plants: evidence from 47 pairs of invasive and non-invasive plants. Science of The Total Environment, 723, 7. https://doi.org/ 10.1016/j.scitotenv.2020.137829.

Karban, R. and Agrawal, A.A. (2002) Herbivore offense. Annual Review of Ecology and Systematics, 33, 641-664. https://doi.org/10.1146/annurev.ecolsys.33.010802.150443.

Karban, R., Baldwin, I.T., Baxter, K.J., Laue, G. and Felton, G.W. (2000) Communication between plants: induced resistance in wild tobacco plants following clipping of neighboring sagebrush. Oecologia,125(1), 66-71. https://doi.org/10.1007/PL00008892.

Keane, R.M. and Crawley, M.J. (2002) Exotic plant invasions and the enemy release hypothesis. Trends in Ecology $\& 3$ Evolution, 17(4), 164-170. https://doi.org/10.1016/S0169-5347(02)02499-0.

Kim, Y.O., Johnson, J.D. and Lee, E.J. (2005) Phytotoxic effects and chemical analysis of leaf extracts from three Phytolaccaceae species in South Korea. Journal of chemical ecology, 31(5), 1175-86. https://doi.org/10.1007/s10886-005-4255-z.

Kourtev, P.S., Ehrenfeld, J.G. and Haggblom, M. (2002) Exotic plant species alter the microbial community structure and function in the soil. Ecology, 83(11), 3152-3166. https://doi.org/10.2307/3071850.

Lankau, R.A., Rogers, W.E., Siemann, E. (2004) Constraints on the utilisation of the invasive Chinese tallow tree Sapium sebiferum by generalist native herbivores in coastal prairies. Ecological Entomology, 29(1), 66-75. https://doi.org/ 10.1111/j.0307-6946.2004.00575.x. 
Leather, S.R. (1983) Evidence of ovulation after adult molt in the bird cherry-oat aphid, rhopalosiphumpadi. Entomologia Experimentalis Et Applicata, 33(3), 348-349. https://doi.org/10.1111/j.15707458.1983.tb03280.x.

Leather, S.R. and Burnand, A.C. (1987) Factors affecting life-history parameters of the pine beauty moth, Panolis flammea (D\&S): the hidden costs of reproduction. Functional Ecology, 1(4), 331-338. https://doi.org/ 10.2307/2389789.

Lindroth, R.L., Anson, B.D. and Weisbrod, A.V. (1990) Effects of protein and juglone on gypsy moths - growth-performance and detoxification enzyme-activity. Journal of Chemical Ecology, 16(8), 2533-2547. https://doi.org/10.1007/BF01017476.

Liu, X., Peng, K., Wang, A., Lian, C. and Shen, Z. (2010) Cadmium accumulation and distribution in populations of Phytolacca americana L. and the role of transpiration. Chemosphere, 78(9), 1136-41. https://doi.org/10.1016/j.chemosphere.2009.12.030.

Liu, D.F., Chen, L., Chen, C., An, X.K., Zhang, Y.J., Wang,Y., Li, Q.J. (2020) Full-length transcriptome analysis of Phytolacca americana and its congener P. icosandra and gene expression normalization in three Phytolaccaceae species. BMC plant biology, 20(1), 396. https://doi.org/10.1186/s12870-020-02608-9.

Lu, X.M., He, M.Y., Ding, J.Q. and Siemann, E. (2018) Latitudinal variation in soil biota: testing the biotic interaction hypothesis with an invasive plant and a native congener. Isme Journal, 12(12), 2811-2822. https://doi.org/ 10.1038/s41396-018-0219-5.

Macel, M., De Vos, R. C. H., Jansen, J.J., Van, d.P.W.H., \& Van Dam, N.M. (2014) Novel chemistry of invasive plants: exotic species have more unique metabolomic profiles than native congeners. Ecology and Evolution, 4(13), 2777. https://doi.org/10.1002/ece3.1132.

Mack, R.N., Simberloff, D., Lonsdale, W.M., Evans, H., Clout, M. and Bazzaz, F.A. (2000) Biotic invasions: Causes, epidemiology, global consequences, and control. Ecological Applications, 10(3), 689-710. https://doi.org/10.1890/1051-0761(2000)010[0689:BICEGC]2.0.CO;2.

Mayhew, P.J. (2001) Herbivore host choice and optimal bad motherhood.Trends in Ecology \& Evolution, 16(4), 165-167. https://doi.org/10.1016/S0169-5347(00)02099-1.

Mccormick, A.C., Arrigo, L., Eggenberger, H., Mescher, M.C., Moraes, C.M.D. (2019) Divergent behavioural responses of gypsy moth (lymantria dispar) caterpillars from three subspecies to potential host trees.Science report, 9, 12. https://doi.org/10.1038/s41598-019-45201-3.

Patra, J.K., Kim, E.S., Oh, K., Kim, H.J., Kim, Y. and Baek, K.H. (2014) Antibacterial effect of crude extract and metabolites of Phytolacca americana on pathogens responsible for periodontal inflammatory diseases and dental caries. BMC Complement Altern Med, 14, 343. https://doi.org/10.1186/1472-6882-14343.

Pearson, D.E. (2009) Invasive plant architecture alters trophic interactions by changing predator abundance and behavior.Oecologia, 159(3), 549-558. https://doi.org/10.1007/s00442-008-1241-5.

Rane, R.V., Ghodke, A.B., Hoffmann, A.A., Edwards, O.R., Walsh, T.K. and Oakeshott, J.G. (2019) Detoxifying enzyme complements and host use phenotypes in 160 insect species. Current opinion in insect science, 31, 131-138. https://doi.org/10.1016/j.cois.2018.12.008 .

Schaffner, U., Ridenour, W.M., Wolf, V.C., Bassett, T., Muller, C., Muller-Scharer, H., Sutherland, S., Lortie, C.J., Callaway, R.M. (2011) Plant invasions, generalist herbivores, and novel defense weapons.Ecology , 92(4), 829-835. https://doi.org/10.1890/10-1230.1.

Schlaepfer, M.A., Runge, M.C. and Sherman, P.W. (2002) Ecological and evolutionary traps.Trends in Ecology \& Evolution, 17(10), 474-480. https://doi.org/10.1016/S0169-5347(02)02580-6. 
Schlaepfer, M.A., Sax, D.F. and Olden, J.D. (2011) The Potential conservation value of non-native species. Conservation Biology,25(3), 428-437. https://doi.org/10.1111/j.1523-1739.2010.01646.x.

Schuman, M.C. and Baldwin, I.T. (2016) The layers of plant responses to insect herbivores. Annual Review of Entomology, 161,373-394. https://doi.org/10.1146/annurev-ento-010715-023851.

Sedio, B.E., Devaney, J.L., Pullen, J., Parker, G.G., Wright, S.J., \& Parker, J.D. (2020) Chemical novelty facilitates herbivore resistance and biological invasions in some introduced plant species. Ecology and Evolution, 10(16), 8770-8792. https://doi.org/10.1002/ece3.6575.

Sequeira, R. and Dixon, A.F.G. (1996) Life history responses to host quality changes and competition in the Turkey-oak aphid, Myzocallis boerneri (Hemiptera: Sternorrhyncha: Callaphididae). European Journal of Entomology, 93(1), 53-58.

Smedley, S.R. and Eisner, T. (1996) Sodium: A male moth's gift to its offspring. Proceedings of the National Academy of Sciences of the United States of America, 93(2), 809-813. https://doi.org/10.1073/pnas.93.2.809.

Stahl, E., Hilfiker, O. and Reymond, P. (2018) Plant-arthropod interactions: who is the winner? Plant Journal, 93(4), 703-728. https://doi.org/ 10.1111/tpj.13773.

Sun, K.K., Yu, W.S., Jiang, J.J., Richards, C., Siemann, E., Ma, J., Li, B. and Ju, R.T. (2020) Mismatches between the resources for adult herbivores and their offspring suggest invasive Spartina alterniflora is an ecological trap. Journal of Ecology, 108(2), 719-732. https://doi.org/10.1111/1365-2745.13277.

Tasin, M., Betta, E., Carlin, S., Gasperi, F., Mattivi, F., \& Pertot, I. (2011) Volatiles that encode host-plant quality in the grapevine moth. Phytochemistry, 72(16), 1999-2005. https://doi.org/10.1016/j.phytochem.2011.06.006.

Thompson, J.N. (1988) Evolutionary ecology of the relationship between oviposition preference and performance of offspring in phytophagous insects. Entomologia Experimentalis Et Applicata, 47(1), 3-14. https://doi.org/10.1111/j.1570-7458.1988.tb02275.x.

Usmani, K.A. and Knowles, C.O. (2001) DEF sensitive esterases in homogenates of larval and adult Helicoverpa zea, Spodoptera frugiperda, and Agrotis ipsilon (Lepidoptera : Noctuidae). Journal of Economic Entomology, 94(4), 884-891. https://doi.org/10.1603/0022-0493-94.4.884.

Vankosky, M.A., \& Vanlaerhoven, S.L. (2016) Does host plant quality affect the oviposition decisions of an omnivore? Insect Science,24(3), 491-502. https://doi.org/ 10.1111/1744-7917.12317.

Vet, L.E.M. and Dicke, M. (1992) Ecology of infochemical use by natural enemies in a tritrophic context. Annual Review of Entomology, 37, 141-172. https://doi.org/10.1146/annurev.en.37.010192.001041.

Wang, J.J., Tsai, J.H. and Broschat, T.K. (2006) Effect of nitrogen fertilization of corn on the development, survivorship, fecundity and body weight of Peregrinus maidis (Hom., Delphacidae). Journal of Applied Entomology, 130(1), 20-25.https://doi.org/10.1111/j.1439-0418.2005.01030.x.

Wang, L.Y., Bai, L.T., Nagasawa, T., Hasegawa, T., Yang, X.Y., Sakai, J.I et al. (2008) Bioactive triterpene saponins from the roots of Phytolacca americana. Journal of Natural Products, 71(1), 35-40. https://doi.org/10.1021/np078012m.

Ward, S.A. and Dixon, A.F.G. (1982) Selective resorption of aphid embryos and habitat changes relative to life-span. Journal of Animal Ecology, 51(3), 859-864. https://doi.org/10.2307/4010.

Wittstock, U. and Gershenzon, J. (2002) Constitutive plant toxins and their role in defense against herbivores and pathogens. Current Opinion in Plant Biology, 5(4), 300-307. https://doi.org/10.1016/S13695266(02)00264-9.

Xu, H.G., Qiang, S., Han, Z.M., Guo, J.Y., Huang, Z.G., Sun, H.Y., He, S.P., Ding, H., Wu, H. R., Wan, F. (2006) The status and causes of alien species invasion in China. Biodiversity and Conservation, 15(9), 
2893-2904. https://doi.org/10.1007/s10531-005-2575-5.

Xu, X.L., Lv, N.N., Shi, Q., Hu, X.S. and Wu, J.X. (2019) Reproductive adaptation in alate adult morphs of the English grain aphid Sitobion avenae under starvation stress. Scientific Reports, 9, 8. https://doi.org/10.1038/s41598-019-38589-5.

Yi, Y., Dou, G., Yu, Z., He, H., Wang, C., Li, L., Zhou, J., Liu, D.J., Shi, J.Y., Li, G.R. (2018) Z-Ligustilide Exerted Hormetic Effect on Growth and Detoxification Enzymes of Spodoptera litura Larvae.Evidence-based complementary and alternative medicine, 10. https://doi.org/10.1155/2018/7104513.

Zhang, Z.J. and Van Kleunen, M. (2019) Common alien plants are more competitive than rare natives but not than common natives. Ecology Letters, 22(9), 1378-1386. https://doi.org/10.1111/ele.13320 .

\section{Hosted file}

Figures.pdf available at https://authorea.com/users/366373/articles/486160-invasive-planthas-higher-resistance-to-native-generalist-herbivore-than-exotic-non-invasive-congener 